\title{
Assessment of verbal Communication Skills of Healthcare Providers in Obstetric and Gynecological Wards
}

\author{
1Nihal ebrahim Elshiraey 2 Nagwa Ebrahim El Feshawy3 Rafeq Ebrahim Ebrahim \& 4Nahed Fikry \\ Hassan Khedr \\ 1 Nursing specialist, Faculty of Nursing, Mansoura University, Egypt \\ 2 lecturer of Woman's Health and Midwifery Nursing, Faculty of Nursing, Mansoura University, \\ Egypt \\ 3Professor of Obstetric and Gynecological Medicine, Faculty of Medicine, Mansoura University, \\ Egypt. \\ 4 Professor of Woman's Health and Midwifery Nursing, Faculty of Nursing, Mansoura University, \\ Egypt. \\ Corresponding author E-mail: besanwasem22@gmail.com
}

\section{Introduction}

Communication is one of the basic human needs. It can be defined as a process of exchanging information, from the person giving the information to the person receiving the information through verbal and non-verbal channels objective (Baranowska et al., 2021). Verbal Communication is exchange of spoken or written words. It includes sounds, words, language and verbal speaking (Dean \&Fain, 2016). Verbal Communication skills are also a critical prerequisite to successful interprofessional teamwork and collaborative process that are crucial to both clinical practice and health care outcomes (Ahmed et al., 2020).

Verbal Communication plays a vital role in professional disciplines including maternity care. Effective verbal communication skills between women and healthcare providers has a great impact to all aspect of maternity care. Improved communication has been robustly demonstrated to positively correlate with increasing woman satisfaction, positive experience, and improved outcomes (Vedam et al., 2019 \& Hancock, et al., 2020).

Nurse-physician verbal communication is more than just exchanging of information in which common understanding across health care team is established (Austin et al., 2021). It is described as a professional interaction, working together, shared decision making around health issues, formulating collaborative patient care plan in which the actual team's performance is measured (Hancock, et al., 2020). Effective nurse physician communication has positive effects on the quality care provided, such as increased maternal satisfaction with health care system, shortened length of stay (LoS), and decreased adverse events (Murugesu et al., 2021). 


\footnotetext{
Improving quality and safety of maternity care has become a priority for hospitals worldwide in recent decades. Effective verbal communication among healthcare team members is one of the hallmarks of safe and highly reliable patient care (Butler, Fullerton \& Aman, 2020). Nurses and physicians are among the most important health care professional groups in hospital settings. They undertake separate and distinct tasks in clinical practice, yet they are expected to communicate effectively to provide effective and high quality services to all women (Bradley et al., 2019).

Significance:

Communication related patient safety issues has become a global concern. Disruptive verbal communication between nurses and physicians occurs with alarming frequency (Bohren et al, 2017). A lack of effective verbal communication between nurses and physicians can lead to adverse effects such as hospital readmissions, extended length of stay, preventable injury، and death. In contrast, when the level of communication between physicians and nurses increased, mortality and medication error rates decreased, level of satisfaction increased, desired outcome achieved (Jolly et al., 2019). So, it is very essential step to assess verbal communication skills among health care providers and identify all barriers of communication that may disrupt communicating process (Schmiedhofer et al, 2021).

Aim of the study

The present study aimed to assess verbal communication skills of healthcare providers in obstetric and gynecological wards.
}

\section{Research question}

What is the pattern of verbal communication skills of healthcare providers in obstetrical and gynecological wards?

\section{Subjects and Method}

\section{Study design}

Descriptive cross sectional study.

Study setting

The study was implemented at the Obstetric and Gynecological wards (ward 9,10,15,18 and labor) in Mansoura university hospital in Egypt.

Study Sample: Convenient sample 106 (nurse $=66$, physician $=20$, workers $=20$ ) health care providers who are working in obstetrics and gynecology wards.

Tools of data collection:

Three tools were utilized for data collection: The first tool was a Structured Interview questionnaires which designed by the researcher after reviewing the national and international relevant literature the researcher. It included: Socio-demographic data of healthcare providers (age, education level, experience and working unit).

The second tool: The modified

Observational Checklist for Assessment of the communication skills which adapted from Mehran et al, 2013, which consisted of: 30 items include 23 items of verbal communication skills as (Greets and shows interest in patient as a person, Introduce himself, Uses words that show care and concern throughout the interview, ect....) and 7 items of nonverbal communication skills as, (Have neat and tidy personal appearance, Sitting in correct position toward patient, listen patient with patience, ect.......).

The third tool: Perceived Nurse- Physician communication among nurses and physicians. It was adapted from ( Hailu et al. 2016, ) to 
assess the communication among the nurses and physicians working in obstetrical and gynecological wards at Mansoura university hospital. It consisted of 11 items as (physicians difficulties in understanding what nurses mean and nurse difficulties in understanding what physician mean......ect ).

\section{Validity of the study tools:}

The study tools were reviewed by five experts from the faculty of nursing at woman's Health and Midwifery Nursing Department. These expert assessed the tool for clarity, relevance, application, comprehensive, and understandable. Changes were considered according to their comments.

\section{Reliability of the tools:}

Reliability of the study tools was tested for its internal consistency by using cronbach's Alpha test. The Cronbach Alpha values of verbal communication skills was: Nurses: 0.860, Physician: 0.867, Workers: 0.843

\section{Preparatory Phase}

An official letter from the faculty of nursing, Mansoura University had been directed to Mansoura University Hospitals director and Head of obstetrics and gynecology department to obtain official permission for conducting the study after explaining the aim and scope of the study. Thereafter, the pilot study was carried out of $10 \%$ of the study participants to a certain the clarity and the applicability of the tool, it also helped to find out any obstacles and problems that might interfere with data collection, based on the finding of the pilot study, certain modification of the tools were done.

\section{Data Collection Phase:}

The researcher attended the study setting three days weekly. The researcher introduced herself to the head nurses to the study setting (ward 9, ward 10, ward 15, ward 18 and labor ward), and explained the study nature checked its legibility for the study and filled the structured interviewing questionnaire. The data was collected of health care providers of physician, nurse and worker that present at the same shift. The researcher went first to labor unit and observe physician, nurse and worker during their verbal communication with women and with each other once all health care providers was observed the researcher went to ward 9 then, ward 10 , then 15, then 18.During nurse-women encounters, the researcher set in a position where she had a direct view of both the health care providers and woman. The researcher refrained from speaking or showing any verbal and/or nonverbal reactions. Also, recorded the presence or absence of specific behaviors in the checklist. All encounters were observed and the checklist marked by the researcher.

\section{Statistical Analysis}

All statistical analyses were performed using SPSS for windows version 20.0 (SPSS, Chicago, IL). All variables with continuous data showed normal distribution and were expressed in mean \pm standard deviation (SD). Categorical data were expressed in number and percentage. Chi-square test was used for comparison of variables with categorical data. The reliability (internal consistency) of the self-efficacy scale and the student satisfaction about learning method questionnaires was calculated. Statistical significance was set at $\mathrm{p}<0.05$. 
1Nihal ebrahim Elshiraey'et. al

\section{Results}

Table1. The socio demographic characteristics of the nurses $n=66$

\begin{tabular}{|l|c|c|}
\hline & $\mathbf{N}$ & \% \\
\hline Age & & \\
\hline$<30$ years & 27 & 40.9 \\
\hline $30-40$ years & 28 & 42.4 \\
\hline$>40$ years & 11 & 16.7 \\
\hline Mean \pm SD & $31.3 \pm 8.2$ & \\
\hline Years of experience & 25 & 37.9 \\
\hline$<\mathbf{1 0}$ years & 30 & 45.5 \\
\hline $\mathbf{1 0}-\mathbf{2 0}$ years & 11 & 16.7 \\
\hline$>\mathbf{2 0}$ years & $11.8 \pm 5.8$ & \\
\hline Mean \pm SD & & \\
\hline Educational level & 39 & 59.1 \\
\hline Diploma & 27 & 40.9 \\
\hline Bachelor degree & & \\
\hline Working unit & 17 & 25.8 \\
\hline Labor & 16 & 24.2 \\
\hline Ward 9 & 11 & 16.7 \\
\hline Ward 10 & 10 & 15.2 \\
\hline Ward 15 & 12 & 18.2 \\
\hline Ward 18 & 27 & \\
\hline
\end{tabular}

Table one shows the socio demographic characteristics of the nurses. It was founded that the age of the nurses ranged from 27 to 40 years with average $31.3 \pm 8.2$. (45.5\%) of them had a10-20

years of experience with an average 11.8 \pm 5.8 . More than half of them $(59.1 \%)$ had a diploma education, and about $(25.8 \%)$ working in labor unit.

Table 2. Distribution of the nurse-women verbal communication skills( $n=66$

\begin{tabular}{|c|c|c|c|c|c|c|}
\hline & \multicolumn{2}{|c|}{ Never } & \multicolumn{2}{|c|}{ Sometimes } & \multicolumn{2}{|c|}{ Always } \\
\hline & $\mathrm{n}$ & $\%$ & $\mathrm{n}$ & $\%$ & $\mathrm{n}$ & $\%$ \\
\hline A. Builds a Relationship & 11 & 16.7 & 18 & 27.3 & 37 & 56.1 \\
\hline B. Opens the Discussion & 13 & 19.7 & 40 & 60.6 & 13 & 19.7 \\
\hline C. Gathers Information & 26 & 39.4 & 38 & 57.6 & 2 & 3.0 \\
\hline D. Understands the Patient's Perspective & 43 & 65.2 & 22 & 33.3 & 2 & 3.0 \\
\hline E. Shares Information & 24 & 36.4 & 34 & 51.5 & 8 & 12.1 \\
\hline $\begin{array}{l}\text { F. Reaches Agreement (If new/changed } \\
\text { plan) }\end{array}$ & 25 & 37.9 & 35 & 53.0 & 6 & 9.1 \\
\hline G. Provides Closure & 4 & 6.1 & 7 & 10.6 & 55 & 83.3 \\
\hline
\end{tabular}

distribution of the nurse-women verbal communication skills. As regard building a relationship $56.1 \%$ of nurses always build a relation with their patient. $60.6 \%$ of nurses sometimes open the discussion. Concerning gathering information, 57.6 information, $33.3 \%$ of them sometimes understand patients perspectives and $51.5 \%$ of nurses sometimes share information. And $53 \%$ sometimes reach agreement and $83.3 \%$ provide closure with their patients. 


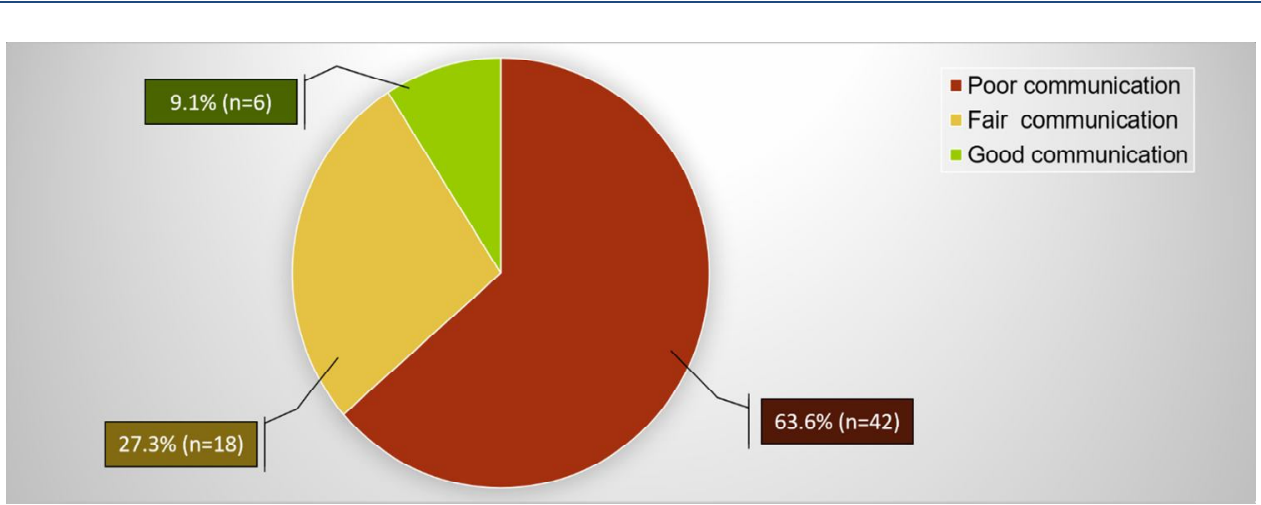

Figure 1. Distribution of the nurse-women total verbal communication skills

Table 3. Association between the nurse-women verbal communication skills and the sociodemographic

\begin{tabular}{|c|c|c|c|c|c|c|c|c|}
\hline & \multicolumn{6}{|c|}{ Nurse-women verbal communication skills } & \multirow{2}{*}{\multicolumn{2}{|c|}{ Chi square test }} \\
\hline & \multicolumn{2}{|c|}{ Poor $(n=42)$} & \multicolumn{2}{|c|}{ Fair $(n=18)$} & \multicolumn{2}{|c|}{ Good $(n=6)$} & & \\
\hline & $\mathbf{N}$ & $\%$ & $\mathbf{n}$ & $\%$ & $\mathbf{n}$ & $\%$ & $\mathrm{X2}$ & $\mathbf{P}$ \\
\hline \multicolumn{9}{|l|}{ Age } \\
\hline$<30$ years & 21 & 50.0 & 6 & 33.3 & $\mathbf{0}$ & 0.0 & & \\
\hline $30-40$ years & 14 & 33.3 & 8 & 44.4 & 6 & $\mathbf{1 0 0 . 0}$ & & \\
\hline$>40$ years & 7 & 16.7 & 4 & 22.2 & $\mathbf{0}$ & $\mathbf{0 . 0}$ & 10.413 & 0.034 \\
\hline \multicolumn{9}{|l|}{$\begin{array}{l}\text { Years of } \\
\text { experience }\end{array}$} \\
\hline$<10$ years & 21 & $\mathbf{5 0 . 0}$ & 4 & 22.2 & $\mathbf{0}$ & $\mathbf{0 . 0}$ & & \\
\hline $10-20$ years & 14 & 33.3 & 10 & 55.6 & 6 & 100.0 & & \\
\hline$>20$ years & 7 & 16.7 & 4 & 22.2 & $\mathbf{0}$ & 0.0 & 12.089 & 0.017 \\
\hline \multicolumn{9}{|l|}{ Educational level } \\
\hline Diploma & 22 & 52.4 & 16 & 88.9 & 1 & 16.7 & & \\
\hline Bachelor degree & 20 & 47.6 & 2 & 11.1 & 5 & 83.3 & 11.861 & 0.003 \\
\hline \multicolumn{9}{|l|}{ Working unit } \\
\hline Labor & 13 & 31.0 & 2 & 11.1 & 2 & 33.3 & & \\
\hline Ward 9 & 11 & 26.2 & 4 & 22.2 & 1 & 16.7 & & \\
\hline Ward 10 & 6 & 14.3 & 4 & 22.2 & 1 & 16.7 & & \\
\hline Ward 15 & 3 & 7.1 & 6 & 33.3 & 1 & 16.7 & & \\
\hline Ward 18 & 9 & 21.4 & 2 & 11.1 & 1 & 16.7 & 9.247 & 0.322 \\
\hline
\end{tabular}

Table Three shows the association between the nurse-women verbal communication skills and the socio demographic characteristics of the nurses. There is a significant association between good verbal communication skills and nurses who were more than 40 years old and who had more than 20 years of experience. As well as, good verbal communication is high among nurses with bachelor degree of education. 
1Nihal ebrahim Elshiraey'et. al

Table (4): The sociodemographic characteristics of the physicians

\begin{tabular}{|l|c|c|}
\hline & $\mathbf{N}$ & \% \\
\hline Age (years) & 6 & 30.0 \\
\hline$<30$ & 9 & 45.0 \\
\hline $30-35$ & $52.3 \pm 4.8$ & 25.0 \\
\hline$>3$ & & \\
\hline Mean \pm SD & 16 & 80.0 \\
\hline Experience & 4 & 20.0 \\
\hline$<5$ years & $1.2 \pm 0.4$ & \\
\hline 5 or more years & & \\
\hline Mean \pm SD & 13 & 65.0 \\
\hline Educational level & 7 & 35.0 \\
\hline Bachelor degree & & \\
\hline Master/Doctorate degree & 6 & 30.0 \\
\hline Working unit & 4 & 20.0 \\
\hline Labor & 3 & 15.0 \\
\hline Ward 9 & 3 & 15.0 \\
\hline Ward 10 & 4 & 20.0 \\
\hline Ward 15 & & \\
\hline Ward 18 & & \\
\hline
\end{tabular}

Table four shows the socio demographic characteristics of the physicians. It was founded that the average age of the physicians was 32.3 \pm 4.8 . $(80 \%)$ of them had less than 5

Table (5): Distribution of physicians- women verbal communication skills $(\mathrm{n}=\mathbf{2 0})$

\begin{tabular}{|l|c|c|c|c|c|c|}
\hline & \multicolumn{2}{|c|}{ Never } & \multicolumn{2}{c|}{ Sometimes } & \multicolumn{2}{c|}{ Always } \\
\hline & $\mathrm{n}$ & $\%$ & $\mathrm{~N}$ & $\%$ & $\mathrm{~N}$ & $\%$ \\
\hline A. Builds a Relationship & 4 & 20.0 & 12 & 60.0 & 4 & 20.0 \\
\hline B. Opens the Discussion & 2 & 10.0 & 14 & 70.0 & 4 & 20.0 \\
\hline C. Gathers Information & 2 & 10.0 & 13 & 65.0 & 5 & 25.0 \\
\hline D. Understands the Patient's Perspective & 5 & 25.0 & 13 & 65.0 & 2 & 10.0 \\
\hline E. Shares Information & 1 & 5.0 & 13 & 65.0 & 6 & 30.0 \\
\hline F. Reaches Agreement (If new/changed plan) & 3 & 15.0 & 15 & 75.0 & 2 & 10.0 \\
\hline G. Provides Closure & 1 & 5.0 & 10 & 5.0 & 9 & 45.0 \\
\hline \multicolumn{7}{|c|}{$24.6 \pm 6.7$} \\
\hline
\end{tabular}

Table five illustrates the distribution of physician- women verbal communication skills. As regard building a relationship $60 \%$ of physicians sometimes open the discussion with their patients. Concerning gathering information, $65 \%$ of them sometimes gathering information. About $65 \%$ of \pm 0.4 . About $(65 \%)$ had a bachalor education, and about (60\%) working in labor unit. them sometimes share information with their patients. And $75 \%$ of the physician sometimes reach agreement and $45 \%$ provide closure with their patients. 


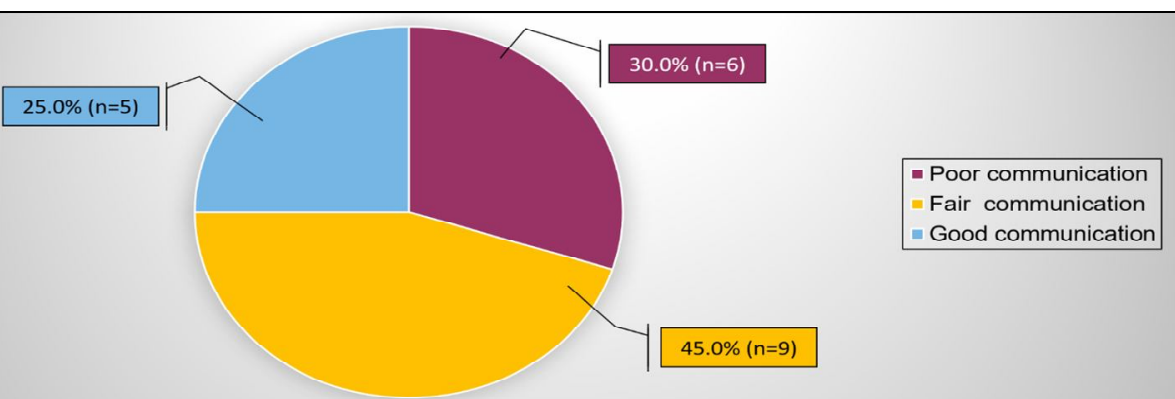

Figure 2. Distribution of the total physician-nurse communication among the doctors

Table 6. The sociodemographic characteristics of the workers $n=20$

\begin{tabular}{|c|c|c|}
\hline & $\mathbf{n}$ & $\%$ \\
\hline \multicolumn{3}{|l|}{ Age } \\
\hline$<35$ years & 6 & 30.0 \\
\hline $35-40$ years & 8 & 40.0 \\
\hline$>40$ years & 6 & 30.0 \\
\hline Mean \pm SD & $39.6 \pm 10.0$ & \\
\hline \multicolumn{3}{|l|}{ Experience } \\
\hline$<10$ years & 8 & 40.0 \\
\hline $10-20$ years & 8 & 40.0 \\
\hline$>20$ years & 4 & 20.0 \\
\hline Mean \pm SD & $13.2 \pm 6.1$ & \\
\hline \multicolumn{3}{|l|}{ Educational level } \\
\hline Primary school & 2 & 10.0 \\
\hline Secondary school & 6 & 30.0 \\
\hline Diploma & 12 & 60.0 \\
\hline \multicolumn{3}{|l|}{ Working unit } \\
\hline Labor & 6 & 30.0 \\
\hline Ward 9 & 7 & 35.0 \\
\hline Ward 10 & 3 & 15.0 \\
\hline Ward 15 & 2 & 10.0 \\
\hline Ward 15 & 2 & 10.0 \\
\hline
\end{tabular}

Table six shows the socio demographic characteristics of the workers. It was founded that the mean age of the workers was $39.6 \pm 10.0$. ( 80 $\%$ ) of them had less than 20 years of experience with an average $13.2 \pm 6.1$. More than half of them $(60 \%)$ had a diploma education, and about (35\%) working in ward 9. 
1Nihal ebrahim Elshiraey'et. al

Table 7. Distribution of the verbal communication skills between the workers and women

\begin{tabular}{|c|c|c|c|c|c|c|}
\hline & \multicolumn{2}{|c|}{ Never } & \multicolumn{2}{|c|}{ Sometimes } & \multicolumn{2}{|c|}{ Always } \\
\hline & $\mathrm{n}$ & $\%$ & $\mathrm{n}$ & $\%$ & $\mathrm{n}$ & $\%$ \\
\hline A. Builds a Relationship & 3 & 15.0 & 9 & 45.0 & 8 & 40.0 \\
\hline B. Opens the Discussion & 15 & 75.0 & 5 & 25.0 & 0 & 0.0 \\
\hline C. Gathers Information & 8 & 40.0 & 9 & 45.0 & 3 & 15.0 \\
\hline D. Understands the Women's Perspective & 16 & 80.0 & 4 & 20.0 & 0 & 0.0 \\
\hline E. Shares Information & 6 & 30.0 & 8 & 40.0 & 6 & 30.0 \\
\hline F. Reaches Agreement (IF new/changed plan) & 18 & 90.0 & 2 & 10.0 & 0 & 0.0 \\
\hline G. Provides Closure & 1 & 2.0 & 14 & 70.0 & 5 & 25.0 \\
\hline
\end{tabular}

Table (7) illustrates the distribution of workers-women verbal communication skills. As regard building a relationship $45 \%$ of the workers sometime build a relation with their patient and one quarter of the workers sometimes open the discussion with the patients. Concerning gathering information, $45 \%$ of workers sometimes gather information, $20 \%$ of them sometimes understand patients perspectives and $40 \%$ sometimes share information. Considering reach agreement, $90 \%$ of them reach agreement with their patients and $70 \%$ provide closure with their patients.

\section{Discussion}

Effective verbal communication is the core of all concerns between health care providers each other's and between health care providers and their patients. Verbal Communication helps in the provision of clear, accurate, consistent and easy nursing service, guaranteeing both the satisfaction of the patients and the protection of the nurses (Ahmed et al., 2020). The aim of the current study was to assess verbal communication skills of health care providers in obstetrics and gynecological wards. The study aim was supported by the study finding as the nurses-women communication skills ranged from fair to poor communication skills. Also, Physicians-women communication skills
(Bullington et al., 2019).

Concerning the socio demographic characteristics of the nurses. The current study revealed that the age of the nurses ranged from 27 to 40 years with average $31.3 \pm 8.2 .45 .5 \%$ of nurses had a 10-20 years of experience with an average $11.8 \pm 5.8$. More than half of them $(59.1 \%)$ had a diploma education, and about (25.8\%) working in labor unit. This finding was consistent with Hailu et al., (2016) who conducted a study to assess nurse-physician communication and the associated factors in Ethiopia and reported that the majority of nurse's age ranged from 25 31 years. About half of nurses had a diploma education and but about half of them had 3-5 years of experience with a mean of $5.57 \pm 6.085$ years. As well as Alimoradi et al., (2013) who carried a research to evaluate midwives verbal and nonverbal communication skills and reported that age of midwives ranged from 22 to 47 years with a mean work experience was 8.46 years. Most of them had a bachelor degree from governmental universities.

Concerning total scores of nurseswomen verbal communication skills, this study found that more than half of the nurses had poor verbal communication skills, less than one third had fair communication skills and the minority of 
them had good verbal communication skills with their patients. These results are in agreement with Alnuaimi et al., (2019) who performed a study to explore women- nurses' interaction at the antenatal clinics in Jordan and concluded that total communication skills among nurses and women were ranged from fair to poor communication as there was lack in many items of verbal communication skills among nurses and women. As well as, Alimoradi etal., (2013) showed that more than have of midwives had undesirable total verbal communication skills toward their clients.

Considering the socio demographic characteristics of the physicians. The current study showed that about half of the physicians were 30 35 years old with an average $32.3 \pm 4.8$. The majority of them had less than 5 years of experience with an average 1.2 \pm 0.4 . About two-third of them had a bachelor degree of education, and more than half of them worked in labor unit. This finding was consistent with Hailu et al., (2016) who conducted a study to assess nurse-physician communication and its associated factors in Ethiopia and reported that the more than half of the physicians were aged from 25-31 years. About half of physician had a bachelor education and but about half of them had 3-5 years of experience.

Regarding, distribution of physician- women verbal communication skills. As regard building a relationship, two-thirds of physicians sometimes used words that show care and concern throughout the interview and the majority of them sometimes speak in a calm and gentle manner. Concerning gathering information, majority of physicians sometimes summarizes and gives patient opportunity to correct or add information. About two-thirds of them sometimes understand patient's perspectives and share information with their patients. Most of the physician sometimes reach agreement and about half of them provide closure with their clients. Also, the current study revealed that total physician-woman communication scores ranged from fair to $\operatorname{good}(50 \%$ to $15 \%$ respectively). These results were in the same line with Tan et al., (2017) who conducted an integrative review to assess nursephysician communication skills and found that there was an ineffective communication pattern among physicianwomen interaction and there was a lack of inter-professional skills during physician communication. Moreover, the present study finding was supported by Taylor et al., (2014) who conducted an observational study to assess communication skills among hospital staff and reported that verbal communication skills of physicians need to improved and additional perspective was required to improve communication skills among health care providers. In contrast, Matziou et al., (2014) who carried out a research to assess the interprofessional communication skills of health care providers and reported that there was an effective pattern of verbal communication skills of physician toward women. Proper skills were more noticed in the respected way of interaction, information given, and providing opportunity to client's interaction during conversation. The disparate views between the current study and other studies may be due to different of training backgrounds of health care providers that confound the effectiveness of current interventions or strategies.

Regarding distribution of the physician- nurse communication among 


\section{Nihal ebrahim Elshiraey'et. al}

the physicians. The present study noticed that there were a high percentage of physicians hadn't difficulties in understanding what nurses mean. Most of them received correct information from nurses. Concerning frustration and interaction, Also, Most of them never feeling angry with nurse's interaction and felt respected after interacting with nurses. These results were supported by Nair et al., (2012) who asses nursesphysicians interactive behaviors in health care wards and found that the total scores of communication between the physician and nurses was effective. Most of physician reported of being satisfied after their interaction with the nurses. This finding was supported by Hailu et al., (2016) who revealed that the majority of the study participants always or usually did not feel angry after their interaction with nurses and other health care team members. These results also was consistent with Alimoradi et al., (2013) who reported that effective communication skills was very effective among midwives and physicians in maternity care units. Similarly, Hailu et al., (2016) showed that most of them always or usually felt understood, respected, pleased and satisfied after interaction with their colleges. Most of physicians always or usually felt understood equal and joyful with work place interaction.

As regard the distribution of workers-women verbal communication skills. The current study illustrated that about half of the workers sometimes build a relationship with their patient. One quartile of them sometimes open the discussion with the clients. Concerning gathering information, less than half of the workers sometimes gather information, understand patient's perspectives or share information with the patients. Considering reach agreement, most of them reach agreement and provide closure with their clients. Regarding total workers-women verbal scores of communication, only less than half of the workers who had a fair communication with their patients. The current study results was in the same line with Bolde et al., (2017) who conducted a qualitative research to assess health care providers attitudes and mistreatment during child birth and reported that there was a mistreatment reported by laboring women as health care workers not provide essential information regarding admission process or treatment plan. Furthermore, the present study result was in agreement with Madula et al., (2018) who reported that some participants at a private health facility indicated that some healthcare workers had a bad attitude and communicated to them poorly. Interestingly,. Those participants described their lack of desire to utilize that health facility again in future.

Finally, Maternity care covers most of women life cycle that starts from preconception till after menopause. Effective verbal communication of health care providers encourage women to continue receiving the appropriate care and seeking health care facilities. So, effective communication skills are the core of high quality maternity care.

\section{Conclusion}

Based on the study findings, it is concluded that assessment of health care provider's verbal communication skills in maternity wards was very important to identify gaps of communication process that need to be addressed. The current study concluded that verbal communication skills of health care provides toward women were relatively poor. While, communication skills 
between health care providers were relatively good. Also there was a statistically significant difference between good verbal communication scores and health care providers who aged more than thirty-five years, who had long years of experience and who had higher level of education.

\section{Recommendation}

Based on the study findings, the study is recommended the following:-

- Different models of teaching communication skills should be designed and executed among health care providers to establish the best and most effective method of training communicative behaviors in maternity care.

- Interim training programmes should be implemented regularly that focus on strengthen the weak points in communication process of health care providers.

- Develop a guideline regarding effective nurse-physician communication skills, and disseminating among nursing and medical team in order to increase their knowledge regarding importance of effective communication skills.

\section{Acknowledgement}

The researchers would like to thank all participants for their cooperation during the study.

\section{References}

Ahmed, H. M. (2020). Role of verbal and non-verbal communication of health care providers in general satisfaction with birth care: a cross-sectional study in government health settings of Erbil City, Iraq. Reproductive Health, 17(1), 1-9. https://doi.org/10.1186/s12978020-0894-3.
Alimoradi, Z., Taghizadeh, Z., Rezaypour, A., \& Mehran, A. (2013). Evaluation of midwives' communication skills. African Journal of Midwifery and Women's Health, 7(1), 19-24.

Alnuaimi, K., Oweis, A., \& Habtoosh, H. (2019). Exploring woman-Nurse interaction in a Jordanian antenatal clinic: A qualitative study. Midwifery, 72, 1-6.

Austin, L., Littlemore, J., McGuinness, S., Turner, S., Fuller, D., \& Kuberska, K. (2021). Effective Communication Following Pregnancy Loss: A Study in England. Cambridge Quarterly of Healthcare Ethics, 30(1), 175-187.

Baranowska, B., Pawlicka, P., Kiersnowska, I., Misztal, A., Kajdy, A., Sys, D., \& Doroszewska, A. (2021). Woman's Needs and Satisfaction Regarding the Communication With Doctors and Midwives During Labour, Delivery and Early Postpartum.

Bohren MA, Vogel JP, Tunçalp Ö, et al. (2017). Mistreatment of women during childbirth in Abuja, Nigeria: a qualitative study on perceptions and experiences of women and healthcare providers Prof. Suellen Miller. Reprod Health. 2017; 14(1): 1 - 13.

Bradley S, McCourt C, Rayment J, Parmar D. (2019). Midwives' perspectives on (dis)respectful intrapartum care during facility- based delivery in sub- Saharan Africa: a qualitative systematic review and meta- synthesis. Reprod Health. 2019; 16(116): 1 - 16. 
Butler, M. M., Fullerton, J., \& Aman, C. (2020). Competencies for respectful maternity care: Identifying those most important to midwives worldwide. Birth, 47(4), 346-356.

Hailu, F. B., Kassahun, C. W., \& Kerie, M. W. (2016). Perceived nurse-physician communication in patient care and associated factors in public hospitals of jimma zone, South West Ethiopia: Cross sectional study. PloS one, 11(9), e0162264.

Hancock, J. T., Naaman, M., \& Levy, K. (2020). AI-mediated communication: definition, research agenda, and ethical considerations. Journal of Computer-Mediated Communication, 25(1), 89-100.

Jolly Y, Aminu M, Mgawadere F, van den Broek N. (2019). "We are the ones who should make the decision" - knowledge and understanding of the rights $\square$ based approach to maternity care among women and healthcare providers. BMC Pregnancy Childbirth. 2019; 19(42): 1 - 8.

Madula, P., Kalembo, F.W., Yu, H. et al. Healthcare providerpatient communication. (2018). a qualitative study of women's perceptions during childbirth. Reprod Health 15, 135 (2018). https://doi.org/10.1186/s12978018-0580-X

Matziou, V., Vlahioti, E., Perdikaris, P., Matziou, T., Megapanou, E., \& Petsios, K. (2014). Physician and nursing perceptions concerning interprofessional communication and collaboration. Journal of Interprofessional Care,
28(6),

$526-533$.

https://doi.org/10.3109/

13561820.2014 .934338 .

Murugesu, L., Damman, O. C., Derksen, M. E., Timmermans, D. R., de Jonge, A., Smets, E., \& Fransen, M. P. (2021). Women's Participation in Decision-Making in Maternity Care: A Qualitative Exploration of Clients' Health Literacy Skills and Needs for Support. International Journal of Environmental Research and Public Health, 18(3), 1130.

Nair DM, Fitzpatrick JJ, McNulty R, Click ER, Glembocki MM. (2018). Frequency of nursephysician collaborative behaviors in an acute care hospital. Journal of interprofessional care. 2012;26(2):115-20. pmid:22145999.

Tan, T. C., Zhou, H., \& Kelly, M. (2017). Nursephysician communication An integrated review. Journal of Clinical Nursing, 26(23-24), 3974-3989. https://doi.org/10.1111/jocn.13832

Taylor, S. P., Ledford, R., Palmer, V., \& Abel, E. (2014). We need to talk: An observational study of the impact of electronic medical record implementation on hospital communication. BMJ Quality \& Safety, 23 (7), 584-588. https://doi.org/10.1136/bmjqs2013-002436.

Vedam S, Stoll K, McRae DN, et al. (2019). Patient- led decision making: measuring autonomy and respect in Canadian maternity care. Patient Educ Couns. 2019; 102(3): 586- 594. 